This is an electronic reprint of the original article. This reprint may differ from the original in pagination and typographic detail.

Author(s): Jokinen, Jussi

Title: $\quad$ Emotional user experience : Traits, events, and states

Year: $\quad 2015$

Version:

Please cite the original version:

Jokinen, J. (2015). Emotional user experience : Traits, events, and states.

International Journal of Human-Computer Studies, 76(April), 67-77.

https://doi.org/10.1016/j.ijhcs.2014.12.006

All material supplied via JYX is protected by copyright and other intellectual property rights, and duplication or sale of all or part of any of the repository collections is not permitted, except that material may be duplicated by you for your research use or educational purposes in electronic or print form. You must obtain permission for any other use. Electronic or print copies may not be offered, whether for sale or otherwise to anyone who is not an authorised user. 


\section{Author's Accepted Manuscript}

Emotional user experience: Traits, events, and states

Jussi P.P. Jokinen

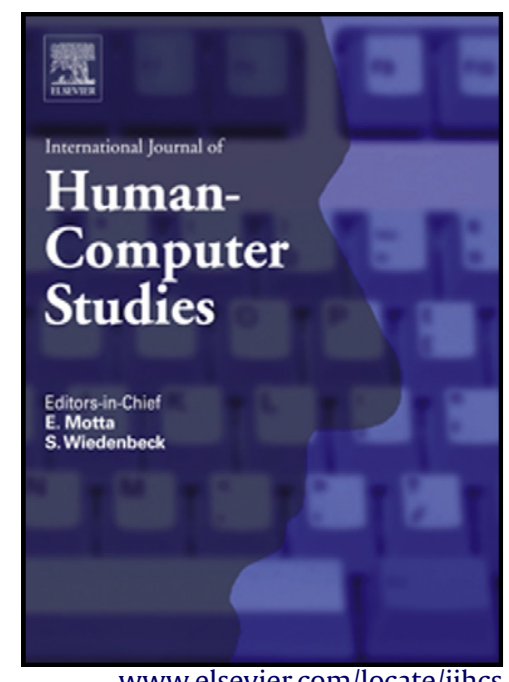

PII:

S1071-5819(14)00169-4

DOI: $\quad$ http://dx.doi.org/10.1016/j.ijhcs.2014.12.006

Reference: YIJHC1920

To appear in: Int. J. Human-Computer Studies

Received date: 11 March 2014

Revised date: 19 December 2014

Accepted date: 22 December 2014

Cite this article as: Jussi P.P. Jokinen, Emotional user experience: Traits, events, and states, Int. J. Human-Computer Studies, http://dx.doi.org/10.1016/j. ijhcs.2014.12.006

This is a PDF file of an unedited manuscript that has been accepted for publication. As a service to our customers we are providing this early version of the manuscript. The manuscript will undergo copyediting, typesetting, and review of the resulting galley proof before it is published in its final citable form. Please note that during the production process errors may be discovered which could affect the content, and all legal disclaimers that apply to the journal pertain. 


\title{
Emotional user experience: Traits, events, and states
}

\section{Jussi P.P. Jokinen ${ }^{\mathrm{a}}$}

a: Jussi P. P. Jokinen, Department of Computer Science and Information Systems, University of Jyväskylä, Finland.

Corresponding author: Jussi P. P. Jokinen

Contact email: jussi.p.p.jokinen@jyu.fi

Address: Department of Computer Science and Information Systems, University of Jyväskylä, Box 35, 40014 Jyväskylä

Tel: +358408053670.

\begin{abstract}
Emotional experience has become an important topic in human-technology interaction research and design. Nevertheless, such research and design often lacks a proper explanatory basis and methodologically robust operationalisation. In this article, a conceptualisation of emotional user experience is formulated based on the appraisal theory of emotion, where the goal congruence of the interaction events and the task-independent individual traits are thought to underlie the user's emotional response. A laboratory study with $N=50$ participants conducting ordinary computer tasks is reported. The results suggest that subjective emotional experience depends on a number of factors relating to individual differences in coping and task events. Emotional user experience, as analysed according to a
\end{abstract}


competence-frustration model of emotion, is dependent on the user's technological problemsolving tendency, frustration tendency, pre-task self-confidence, and task performance.

Keywords: emotion; appraisal; user experience; human-technology interaction; coping; individual differences

\section{Introduction}

\section{The appraisal process and emotion in human-technology interaction}

Subjective experience has recently received much attention in human-technology interaction research and design. Moreover, terms such as user experience have been introduced to emphasise the importance of the feelings that users experience as they interact with technological artefacts (Bødker, 2006; Hassenzahl, 2010; Desmet and Hekkert, 2007; Norman, 2004; Wright et al., 2008). Most scholars in the field agree that emotion is one of the main dimensions of user experience (Bargas-Avila and Hornbæk, 2011; Hassenzahl and Tractinsky, 2011; Norman, 2004; Saariluoma and Jokinen, 2014; Thüring and Mahlke, 2007). However, a psychologically valid theory of emotional user experience is still lacking (Saariluoma and Jokinen, 2014). This shortcoming is especially visible in empirical studies, where theoretical operationalisation of emotional user experience would be required (BargasAvila and Hornbæk, 2011). One problem resulting from the lack of a complete and theoretically sound operationalisation of emotional user experience is that more room is left for pre-scientific intuitions to affect the design of experiments and new interaction technologies (Saariluoma, 1997). With clearer systematic operationalisations, humantechnology interaction researchers and designers could better explicate and conceptualise their intuitions concerning such elusive concept as subjective experience, thus benefiting the 
field from both the perspective of basic research and applied design (Saariluoma, 1997;

Saariluoma and Jokinen, 2014; Saariluoma and Oulasvirta, 2010).

The capacity of psychological theory to explain why people have certain emotional experiences or behave in certain ways is one of the most critical prospects for conceptualising emotional user experience in psychological terms (Saariluoma, 2004). While the prospect is obviously important for scientific pursuits, it is also important in the design process, as showing how and why certain experiences occur in human-technology interaction lets designers create concepts and test their ideas theoretically, giving a formal basis for design solutions. This is highly important, for example, in experience-driven design (Hekkert et al., 2003), where being able to evaluate concepts theoretically in the very beginning of the design process is essential. In the same manner, as an engineer utilises scientific concepts and laws while making construction plans, an interaction designer needs to be able to utilise psychological concepts and theories concerning human-technology interaction (Saariluoma and Oulasvirta, 2010).

Although there is much discussion about measuring emotion and user experience, many researchers and designers still think that the operationalisation of valid user experience measurement instruments is not possible (Law et al., 2014). This is understandable for two reasons. First, emotion is still a debated topic in psychological theory. Interest in emotion has always been a part of philosophical and scientific inquiries, but the theoretical and experimental psychology of the last century focused mainly on other aspects of human mental life, especially on the information-processing aspect of human cognition (Baddeley, 2007; Power and Dalgleish, 1997). Only recently there has been a proliferation of emotion research, but despite this increased interest, fundamental disagreements on what emotion actually is still exist (Barrett, 2006; Izard, 2007; Scherer, 2009). Disputes arise between positions, such as there is a set of biologically hard-wired basic emotions (Izard, 2007), 
emotion is the result of a complex process of cognitive computation (Scherer, 2009), and conscious emotional experience is a conceptual and cultural reflection of a core physiological valence-arousal structure (Barrett, 2006; Russell, 1980). Many of these and other perspectives on what emotion is have been considered in human-technology interaction research (Lichtenstein et al., 2008; Mahlke and Minge, 2008), and it seems that it is too early for interaction researchers to side with a single psychological theory of emotion. In this article, appraisal theory is utilised (Scherer, 2009), but its use reflects its practical value in understanding emotional user experience as a process more so than an exclusive commitment to its meta-theoretical foundations.

The second apparent reason for reluctance to theorise and operationalise emotional user experience stems from the foundational notion that user experience is holistic (Hassenzahl and Tractinsky, 2008). This notion entails that user experience is all encompassing, contextual, and non-reducible, which makes a dimensional analysis of user experience and its subsequent operationalisations conceptually difficult (Boehner et al., 2007). The objective study of subjective experience indeed has methodological challenges associated with both the nature of consciousness and the quality of experience. Subjective experience is private and immediate, and it seems impossible or at least extremely difficult to put experience into explicit words and to analyse it objectively (Dennett, 1988). However, it is maintained here that emotional user experience can be theorised in psychological terms and that valid operationalisations of it can be used to measure emotional experience during or after technology use. This assumption, of course, entails a theoretical and a methodological question: what is emotion, and how can it be studied?

The standardised definition suggests that user experience is an individual's response to the use of technology (ISO 9241-210; Law et al., 2009), and, in such definition, it is therefore assumed that experience - emotional or otherwise - occurs in a process (see also Roto et al., 
2011). A psychological theory of emotional user experience would hence benefit from an approach that would explain emotion as likewise occurring in a process. Suitably, one of the influential theories of emotion, appraisal theory, states that emotion can be understood as a cognitive process (Power and Dalgleish, 1997; Scherer, 2009; Scherer et al., 2001). Appraisal theory proposes that emotion arises as a function of meaning structures, which are used to evaluate, or appraise, the personal significance of an event (Frijda, 1988; Lazarus, 2001; Scherer, 2005, 2009). This proposition focuses on the subjective interpretation of the event when explaining emotion, a perspective that is in line with the general user experience discourse. Hence, it further supports the use of appraisal theory as the theoretical framework for a psychology of emotional user experience.

While the process of appraisal consists of multiple levels, layers, interconnections, and phases (Scherer, 2009), two main appraisal types can be explicated (Lazarus, 2001; Lazarus et al., 1970). The first, primary appraisal, refers to the evaluation of a situation from the perspective of personal goals and values. Primary appraisal establishes the subjective significance, or meaning, of an event: whether or not the event is relevant to the individual's goals, and whether the event is pleasant or not. In secondary appraisal, the subject's ability to cope with the consequences of the event is assessed; that is, what is the subject's control over the event, and how can the subject adjust to it. These two forms of appraisal are responsible for changes in autonomic physiology, action tendencies, motor expression, and subjective feeling, which produce relevant emotional responses to events (Scherer, 2009). In this paper, appraisal theory is utilised to derive hypotheses concerning goal-congruency of interaction events, and individual differences in coping traits, both of which are closely related to the appraisal process. The experimental investigation will focus on how traits, events, and states influence the appraisal process, which explains emotion responses during human-technology interaction. 
To understand how people consciously experience their emotions, a distinction between an implicit emotional process and explicit representation of emotion is necessary. The appraisal process is largely unconscious; it occurs without our explicit knowledge of it (Scherer, 2009). However, we are conscious of our emotions and are able to explicate our emotional experience. In the appraisal model, conscious experience of emotion is called feeling (Scherer, 2005, 2009), which can be defined as a mental representation of an emotional experience (Saariluoma and Jokinen, 2014; Scherer, 2005). Mental representations are entities that are about something, and, in this case, they are about emotional states. The emotional content of a mental representation refers to the conscious experience of emotional states. Some of the states occur more frequently than others do, and these are called modal states (Scherer, 1994, 2005). Modal emotions such as anger, fear, or joy are not assumed to be from a small set of physiologically hard-wired emotions, as posited in the theory of basic emotions (Scherer, 1994, 2005; c.f. Ekman, 1993; Izard, 2007). Basic emotion theory is nevertheless useful in operationalising and understanding the most important emotions associated with human-technology interaction, because research in its framework has a long tradition of identifying and describing these emotions (Saariluoma and Jokinen, 2014).

Emotional contents of mental representation are the methodological key to both the study of emotional user experience, and explanation of emotion in human-technology interaction (Saariluoma and Jokinen, 2014). Assuming that mental representations cause other mental states and behaviour (Fodor, 1985), the emotional contents of mental representation can be used to explain thinking and behaviour. In human-technology interaction, the user appraises the events of the interaction. This is a continuous and mostly unconscious process, but the user is able to mentally represent emotional states and thus have a conscious emotional experience. The contents of these representations can vary, but, as discussed previously, a certain set of modal (or 'basic') emotions is familiar to all of us and 
frequently useful in describing our feelings (Ekman, 1993; Saariluoma and Jokinen, 2014; Scherer, 2005). Emotional user experiences can therefore be investigated by asking the users to verbalise or otherwise indicate the emotional contents of their mental representations in terms of these modal emotions. Protocol analysis (Ericsson and Simon, 1984) and questionnaires (Saariluoma and Jokinen, 2014; Schorr, 2001), for example, are established means of obtaining information concerning the contents of mental representations.

\section{The competence-frustration model of emotional user experience}

Any appraisal process starts with an event, which starts the cognitive process in which the subjective relevance of the event and the person's coping capacity are evaluated (Scherer, 2005). An example of such an event and subsequent emotional response in humantechnology interaction is the positive correlation between task performance and user satisfaction (Hornbæk and Law, 2007). Generally, successful events during the use of technology are appraised as pleasant because they are congruent with the goals of the user. On the contrary, frustration, anxiety, and confusion arise when there are obstructions in the interaction, and these are appraised as incongruent with the goals of the user. The relation of emotional user experience to interaction events can be analysed with the bipolar competencefrustration model, in which feelings of competence (or techno-competence) arise from successful task completion and the users perceiving their own skills in a positive light, whereas, frustration (or techno-frustration) is the result of being obstructed and unable to accomplish task goals (Saariluoma and Jokinen, 2014).

The main benefit of using the competence-frustration model is that it is grounded on the psychological theory of emotion, and, hence, it supports the goals of the study. Methodologically, appraisal theory posits that the key to user's conscious experiences is in the subjective feeling component of appraisal (Scherer, 2009). This component is theorised as the emotional content of a mental representation. This is the same starting point as in the 
competence-frustration model, where the concept of mental representation is used to formalise how people experience interactive events (Saariluoma and Jokinen, 2014). Further, the competence-frustration model has been constructed for the domain of human-technology interaction, and as such, it is more concentrated on the topic of this study than more general models of emotions, such as the positive and negative affect schedule (Watson et al., 1988). However, it should be noted that the choice of competence-frustration model does not mean, that other emotions would not be possible in human-technology interaction. Instead, as will become evident below when discussing secondary appraisal, both competence and frustration fit well into the investigation of primary and secondary appraisal.

Appraising the pleasantness of an interaction event is the primary part of the appraisal process in human-technology interaction. Task effectiveness leads to techno-competence, and, because accomplishing tasks is congruent with the goals of the users, the users perceive that their accomplishments are due to their skills and knowledge (Saariluoma and Jokinen, 2014). Feelings of competence are closely related to self-efficacy, which is the self-appraisal of operational capability or the self-referential representation about the capabilities of the subject to perform in a given domain (Bandura 1977, 1982). Self-efficacy is therefore closely linked to feelings of competence: both refer to the individual's self-perceived capacities. However, competence is not the same as self-efficacy. Whereas self-efficacy refers to people's beliefs in their own operational abilities, competence is the emotional associate of the successful employment of such abilities (Saariluoma and Jokinen, 2014).

Primary appraisal of an interaction event can also result in a negative emotional response, such as anxiety or frustration. Frustration is the result of a goal-incongruent event or obstruction (Saariluoma and Jokinen, 2014). Reflecting the subjective nature of the appraisal process, the same obstructive event may result in different amounts of frustration, depending on how important the obstructed goal was to the user. What is important is that 
frustration as an emotional user experience response presupposes the existence of a subjective goal, and an event that the user perceives as obstructive. In other words, experiencing frustration requires conscious attribution of the source of the frustration to an obstructive event (Scherer, 2001, 2009). In acute forms, this can lead to aggressive behaviour towards the attributed source of frustration (Berkowitz, 1989), as demonstrated in human-computerinteraction research (Brinks, 2005; Lazar et al., 2006).

The bipolarity of the competence-frustration model indicates that these two emotional parts of user experience are separated by their valence, which is a basic content-dimension of human emotional experience (Frijda, 1988; Jokinen and Saariluoma, 2014; Russell, 1980). Although events are usually appraised by their valence as either pleasant or unpleasant, competence and frustration are not necessarily negatively correlated. It is possible to imagine a scenario, where an obstructive interaction event causes frustration in the user, but the user is nevertheless able to solve the problem and thus experience competence. In this case, the user's feeling of competence may still be accompanied by frustration, for example if the cause of the obstruction was in a bad interface design. Frustration is indeed empirically associated with how professional, needful, and safe the technology is considered, whereas competence is more associated with the user's own abilities than the features of the technology (Saariluoma and Jokinen, 2014). There is a difference in achieving task performance with effort and with ability (Schunk, 1983), and hence the relation of feeling of competence to successful interaction is more complex than with feeling of frustration.

Research on emotion in human-technology interaction has long maintained that task performance during technology use correlates with emotional responses, and since the 1980s, usability research has produced a strong body of evidence for this association (Hornbæk, 2006; Hornbæk and Law, 2007). Although the competence-frustration model of emotional user experience is theoretically in line with this notion, the model does not currently have 
empirical support for this thesis. The first hypothesis of the study is therefore the validation of the argument that techno-competence and techno-frustration correlate with task performance. The establishment of this association is important for two reasons. First, before empirical support has been provided, the whole competence-frustration measurement model of emotional user experience lacks construct validity in the sense that the correlations expected from the model have not been investigated. Second, it is important to establish the effect sizes of the correlations, that is, the strength of the association between task performance and emotional user experience. The first hypothesis is stated separately for both factors of the competence-frustration model.

H1a. Task performance affects feelings of competence.

H1b. Task performance affects feelings of frustration.

\section{The appraisal process and coping in emotional user experience}

Primary appraisal establishes the personal relevance of the event: goal-congruent events result in pleasant emotional responses, and goal-incongruent events result in unpleasant emotional responses. In secondary appraisal, the user's ability to cope with the event is evaluated. Coping is an important part of the emotional process, and it can be understood as the individual's adaptation effort in managing interaction with the environment (Folkman and Lazarus, 1985; Lazarus, 1991; Lazarus and Lazarus, 1994). In this sense, coping is not associated only with problems and obstructions: the capacity to exert control over the event is appraised in all situations, and it can be relevant in both pleasant and unpleasant situations. Feelings of techno-competence, for example, are the result of being able to control events and perceive the results of the interaction as pleasant. Feelings of techno-frustration, on the contrary, are the result of goal-incongruent obstructions in a situation where the user should have some power over the event. 
People have different strategies for coping, and the choice of a strategy depends on the situation and the individual. There are two general coping strategies: problem-solving and emotion-centred approaches (Folkman and Lazarus, 1985; Lazarus, 1991; Lazarus and Lazarus, 1994). In ideal terms, if a high control potential over an event is appraised, a problem-solving coping strategy can be utilised to influence the event, exert power over it, and make the situation more congruent with personal goals. However, if the power to influence the situation is appraised as low, a better strategy is to attempt to deal with the emotional response (Folkman and Lazarus, 1985). The choice of a strategy is, of course, not dichotomous: successful coping can encompass both problem-solving and emotion-regulation strategies. There are also individual differences in the use frequency of these two strategies (Folkman and Lazarus, 1985).

In human-technology interaction, for example, some users may try to restore their emotional stability after a problematic use event, whereas others may try to push their limits and learn something new during the process (Beaudry and Pinsonneault, 2005). If the problem-solving coping strategy is utilised successfully and, therefore, a goal-congruent state of events is established, the emotional response is positive. For example, solving a problem and understanding that the solution was due to the user's skills and determination causes the user to feel competent (Saariluoma and Jokinen, 2014). This trait is here called planful problem-solving. However, even if the user does not solve the problem, individuals who are able to cope with the frustration response experience less feelings of frustration in the face of goal-incongruent events than do individuals who are not able to cope with their emotions (Lazarus, 2001; Lazarus et al., 1970). This trait is here called frustration tendency. These notions serve as the basis for the second and third hypotheses of this study.

H2. Having a tendency to solve technological problems planfully has a positive influence on competence. 
H3. Having a tendency to get frustrated with technological problems has a positive influence on frustration.

The hypotheses are stated as direct effects of coping traits on emotional response. It is important, however, to understand that while coping traits are an intrinsic part of the appraisal process, they are not the primary cause of emotion. Rather, coping traits moderate the effect of events on emotional response. Frustration, for example, presupposes an event that is appraised as goal incongruent, and coping traits moderate the effect of the event on frustration, by weakening or strengthening the frustration. However, the study is the first of its kind to investigate experimentally coping traits and emotional responses in humantechnology interaction, and establishing the main effect that precedes moderation effects is a priority. Therefore, while $\mathrm{H} 2$ and $\mathrm{H} 3$ are stated as direct effects, it is better to think of the relation as associative rather than causal. The main proposition of the study is the association between coping traits and emotional responses, and the hypotheses relate to it. Detailed study of moderation is left for further studies, which could use the study's findings on coping effects.

\section{Self-confidence and emotional user experience}

Users' emotional responses to the events of an interaction are therefore dependent on their individual coping tendencies. However, there is also within-individual variance in emotional responses to events. Small annoyances during the use of technology can build up to a disproportionately aggressive response to a single obstructing event. Further, the user always comes into the interaction situation with an underlying emotional state, or a mood. Compared to emotions, moods are more persistent in time and lacking a clear antecedent (Sedikides, 1995). Whether a person is in a positive or negative mood has been shown to influence cognitive processes (Bower, 1981), judgments of others (Forgas and Bower, 1987), and self-conceptions (Sedikides, 1995). Mood is also considered an important antecedent of 
user experience (Hassenzahl and Tractinsky, 2006), but the effect of mood on the user's emotional states has not been studied in the same depth as it has been in the context of general psychological research.

Mood affects emotional responses, but it also affects the beliefs individuals have about themselves. A negative mood predicts decreased belief in one's own abilities, whereas a positive mood strengthens this belief (Kavanagh and Bower, 1985). Assessing a person's mood is a challenging problem, preferably requiring multiple repeated measurements to control for day-to-day variance (Watson and Clark, 1997). However, assessing one's belief in one's own abilities is easier. Self-confidence before starting tasks, for example, while not a direct measure of mood, is influenced by the mood of the user and, hypothetically, affects the emotional responses of the user (Kavanagh and Bower, 1985). Although this is not the same as predicting the effect of mood on emotional user experience, it is the starting point of analysing such mechanism. Therefore, the final, two-fold hypothesis of the study is as follows.

H4a. Self-confidence before the use event has a positive influence on competence. H4b. Self-confidence before the use event has a negative influence on frustration. In conclusion, in the user experience literature, user characteristics such as traits and moods have been noted in to influence the user's emotional responses (Hassenzahl and Tractinsky, 2006; Mahlke and Thüring, 2007); however, the influences of individual differences in coping strategies and moods have not been thoroughly investigated in the context of human-technology interaction research. In general, individual differences in human-technology interaction have been acknowledged from the perspective of information processing (e.g., Allen, 2000; Saracevic, 1991), and some research on individual differences on emotional experience exists (Brave and Nass, 2003). In technology acceptance models, for example, individuals' beliefs about their abilities to competently use computers has been 
shown to influence their expectations of computer use and their recollected emotional reactions to computers (Compeau and Higgins, 1995; Shu and Wang, 2011). Further studies have extended this model, demonstrating a connection between the individuals' fears concerning computer use and their perceived ease of use in technology adoption (Venkatesh, 2000, 2008).

These models consistently show associations between user traits and emotional responses towards technology; however, they do not observe these responses at the time of use nor connect them with use events. Therefore, it is difficult to analyse the confounding effects of individual dispositions and use events on emotional responses. In other words, with such models, it is difficult to explain the user's emotional response and resulting behaviour. What is the mechanism, for example, between fear of using computers and perceived ease of use? Does the 'fear trait' lead to poor performance, which leads to perceived difficulties in use, or do the technology-use traits correlate with emotional responses regardless of effectiveness? A detailed model of emotional user experience, taking into account the individual antecedents in sources of variance, such as coping and mood, is still missing.

\section{Method}

\section{Participants, stimuli, and procedure}

$N=50$ participants (37 men and 13 women) were recruited for the experiment (age $M=$ 22.8 years, $S D=5.0$, and range $=18-43$ ). The participants were university students, recruited from an introductory course for human-technology interaction. A day before coming to the laboratory, the participants were asked to answer a questionnaire concerning the traits they use to cope with technology (the questionnaire was filled online). In addition, the participants reported their self-confidence at the start of the experiment. In the experiment, the participants conducted tasks using four desktop applications used in everyday office work 
and then reported their emotional states during the tasks. Four points of data were therefore attained and used to investigate the hypotheses: coping traits of the user (a questionnaire administered a day before the experiment), self-confidence of the user (a questionnaire administered just before the experiment), events of the use (recorded at the time of the use), and emotional responses to the use (a questionnaire administered immediately after the use).

The tasks were conducted with four applications: a text processor (Microsoft Office 2010 Word), an image editor (Microsoft Paint), a presentation editor (Microsoft Office 2010 PowerPoint), and an internet browser (Google Chrome). All four have been associated with workplace frustration (Lazar et al., 2006), which supports their usefulness in studying emotional user experience. Ordinary desktop applications and tasks were chosen because most people are familiar with the context. Indeed, each participant had at least some experience with each of the applications used in the experiment, and everyone reported having at least basic computer skills. The tasks ranged from opening and saving a document or adding a new presentation slide, to drawing an ellipse of a certain colour. All tasks were possible to do without advanced computer skills, but some required more thinking and problem solving than the others did. Participants were given one task at a time to complete, and five minutes for each application. Task completion was confirmed by the experimenter, who then gave the participant a new task. At the end of the five minutes, the number of completed tasks was recorded and used as a measure for task performance. Task performance was therefore operationalised as the effectiveness of the user (Hornbæk, 2006). After completing tasks for five minutes, the participants were given a questionnaire regarding emotional user experience. This procedure was repeated four times for each participant, once for each application. Task order was counterbalanced between the participants by randomisation. 


\section{Questionnaires}

The two technology coping dimensions, problem solving and emotional coping, were operationalised into a questionnaire. All questionnaire items, their factor loadings, and the reliabilities of the scales are presented in Table 1. Previously used coping questionnaires include, for example, the Ways of Coping Questionnaire (Folkman and Lazarus, 1988), for investigating general coping traits, and Computer Self-Efficacy (Compeau and Higgins, 1995; Shu and Wang, 2011) and Computer Anxiety (Venkatesh, 2000) for investigating technology traits specifically. Items from these sources were used to create new scales for the two coping strategies: Planful problem solving and frustration tendency. For example, an item from the Ways of Coping Questionnaire, 'I drew on my past experiences; I was in a similar situation before.' was used as a basis for an item in planful problem solving: 'When I encounter a technological problem, I utilise my prior knowledge and experience in solving it.' Hence, planful problem solving measures the individual's perseverance with problems and capacity for utilising problem-solving resources. Frustration tendency, on the contrary, concerns the individual's tendency to get frustrated with technological problems to the extent that it interferes with the individual's emotional stability and self-control.

Immediately after the participants arrived at the laboratory, self-confidence was measured at the start of the experiment with a four-item Likert-scale. The scale was taken from the competence-frustration model of emotional user experience (Saariluoma and Jokinen, 2014). However, the reliability analysis indicated that the scale for self-confidence was not reliable with the item 'Before the experiment, I felt vigilant'; removing the item resulted in a reliable scale. The questionnaire for emotional user experience was constructed from the bipolar factor model of emotional user experience, consisting of scales for competence and frustration (Saariluoma and Jokinen, 2014). The questionnaire items consisted of four basic or modal emotions for each factor, presented as Likert-scales. 


\section{[Table 1 about here.]}

All factors (planful problem solving, frustration tendency, self-confidence, competence, and frustration) were calculated into summated scales using a regression method for factor scores of a maximum likelihood factor analysis (DiStefano et al., 2009). This practice aims to maximise the reliability of the scale by using an item's factor loadings and its correlations with the others as weights, and results are given in standardised scales with a mean of 0 and variance of approximately 1 . Although the number of participants was relatively small for a factor analysis, the number of items in the factors was likewise small: an individual factor had three or four items, resulting in over ten times as many observations as items. The scales for competence and frustration were calculated by pooling the data from the four tasks.

Both Cronbach's alpha and factor score covariance coefficients were calculated for assessing reliability, whereas factor score covariance coefficient is a better estimator of the reliability of the scale constructed using the regression method (DiStefano et al., 2009; Osburn, 2000), reporting Cronbach's alpha is the standard practice. The alpha of both frustration tendency and self-confidence was slightly below the generally accepted cut-off line of .70 , but the factors were accepted in the analysis, as their factor score covariance was still acceptable. Other factors were acceptable using both measures of reliability. For the factors constructed by pooling the repeated measures data, reliabilities for each repeated measure was calculated to confirm uniform reliability. The reliability of competence was at least .87 , and it was at least .84 for frustration, confirming that the measures were reliable in all tasks. None of the factors described previously were observed to depend on the background variables of the participants, namely age or gender.

\section{Data analysis}

The hypotheses of the study were tested with linear mixed modelling using the 'generalised linear mixed model' procedure in SPSS 20. Separate models with either 
competence or frustration as the dependent variable were constructed. Both models included an intercept, the task performance scale (H1), and the self-confidence scale (H4). Further, the model for competence included the planful problem solving scale (H2), and the model for frustration included the frustration tendency scale (H3). In order to control for confounding interaction effects, such as frustration tendency having an effect on task performance, which then has an effect on frustration, interaction effects between the background variables and task performance were added (all interaction effects are listed in the results section).

However, the two coping traits were not mixed between the models, and, therefore, the model for competence did not include frustration tendency, and the model for frustration did not include planful problem solving. The reason for this is that mixing the models would have greatly increased the number of independent variables and their interactions, which would have affected the model's robustness.

As the models consisted of four repeated measures conducted with the same participants (four different applications), task was included as a random effect in the model and will be reported as random variance in the models. Satterthwaite's (1941) approximation for degrees of freedom was used in the models, as it increases the power of the analysis on small sample sizes in repeated measures testing (Hox, 2010). It assumes heterogeneous sample variances and adjusts degrees of freedom to account for this, which can be seen as different $d f 2$ values between the fixed effects in the results. All 50 participants conducted four tasks each, resulting in 200 cases, but, two participants failed once to fill the emotional questionnaire properly, and these two cases were discarded from the analysis. Therefore, the number of cases included in the two models was 198. Otherwise, there were no missing data.

Finally, it should be noted that the modelling procedure used does not indicate the model fit in terms of $R^{2}$ (Hox, 2010). It is, however, possible to compare models with each other using the Akaike information criterion (AIC): lower numbers indicate better fitting 
models, but the number is relevant only for comparing competing models with each other (Hox, 2010). AIC change when adding the main fixed effects are reported in the results.

\section{Results}

On average, the participants were able to complete 4.5 tasks $(S D=1.3)$. There were no notable differences in task performance between the four desktop applications: the mean task completion were 3.8 for word processing, 5.0 for image manipulation, 4.9 for web browsing, and 4.3 for presentation editing. The maximum number of tasks for each application was 15 , but no one was able to complete all of them in the allocated time. Because the mean of the tasks completed was closer to its theoretical minimum than the maximum, it had a slight positive skew of $.28($ s.e. $=.17)$. However, the distribution was approximately normal, and the residuals from the linear models revealed that the results were not caused by any outliers. The number of tasks completed was not dependent on the age or the gender of the participant, as revealed by non-significant correlation and $t$-tests. Similar analysis for the emotional user experience factors revealed that competence and frustration were not dependent on the computer application, gender, or age.

There was no correlation between the coping traits factors, planful problem solving, and frustration tendency $(r=.04)$. Self-confidence had a small correlation with planful problem solving $(r=.27)$, but not with frustration tendency $(r=.01)$, indicating that the selfconfidence at the start of the experiment was not, at least not largely, dependent on the coping traits of the participant. No correlations between the number of successfully conducted tasks and planful problem solving $(r=.07)$, frustration tendency $(r=.02)$, or self-confidence $(r=$ .04) were observed, indicating that individual differences in coping did not influence task performance directly and suggesting that the tasks were relatively easy to conduct. Although these correlations were not the main interest in the study, the small observable correlation 
between the explanatory variables make the models predicting competence and frustration more robust (Shieh and Fouladi, 2003).

The AIC was 453.9 for the linear mixed model for competence with task performance, 441.7 with task performance and planful problem solving, and 440.1 with task performance, planful problem solving, and self-confidence. The respective AICs for the frustration model, in which frustration tendency was used in place of planful problem solving, were 474.8, 466.5, and 466.1. The decrease in AICs of both models indicates that the main effects increased the model fit. The linear mixed model for competence is displayed in Table 2, and the model for frustration is shown in Table 3, which presents the fixed coefficients of the models with standard errors and standardised coefficients, as well as the random part of the model, signifying the repeated measurements in the experiment.

\section{[Table 2 about here.] \\ [Table 3 about here.]}

The results support $\mathrm{H} 1, \mathrm{H} 2$, and $\mathrm{H} 3$, and give partial support to $\mathrm{H} 4$. Planful problem solving tendency increases competence as hypothesised (H2), and frustration tendency can be used to predict frustration during the use of technology $(\mathrm{H} 3)$. Self-confidence, reported at the start of the experiment, increases competence (H4a), but it has no statistically significant effect on frustration, although the direction of the effect is as hypothesised (H4b). Clearly, however, the largest predictor of emotional user experience in the models is task performance (H1a and b): being able to complete tasks increased competence and decreased frustration. In the competence model, the standardised coefficient of task performance is .63, which is clearly greater than the standardised coefficients of self-confidence (.33) or planful problem solving (.19). In the frustration model, the standardised coefficient of task performance $(-.59)$ is likewise larger than that of frustration tendency (.35). 
The interaction effects, while not stated as hypotheses, and only included in the model as controls, revealed one preliminarily interesting effect. The model suggests that selfconfidence moderates the effect of task performance on competence. Interpreting interaction effects of two continuous variables is difficult (Hox, 2010), and, hence, the interaction is visualised in Figure 1 as a regression of the effects of task performance on competence by two extremities: two standard deviations below the mean self-confidence and two standard deviations above. The interpretation is now easier: those with very little self-confidence at the start of the experiment report, on average, less competence than those with much selfconfidence do, but if they are successful in completing tasks, competence is influenced more than it is for those with more self-confidence.

\section{[Figure 1 about here.]}

\section{Discussion}

\section{Individual coping differences and task performance in emotional user experience}

The empirical results support the hypotheses of the study. The main antecedents of the user's emotional experience, measured as techno-competence and techno-frustration (Saariluoma and Jokinen, 2014), were revealed to be task performance (H1), individual differences in coping traits ( $\mathrm{H} 2$ and $\mathrm{H} 3)$, and, partly, confidence before the experiment (H4a, but not b). The practical implication of the support for $\mathrm{H} 2$ and $\mathrm{H} 3$, and partial support for $\mathrm{H} 4$, is that these effects need to be considered when analysing the effect of technology use on the emotions of the user. Psychological theory on emotion is clear on this matter: there are individual differences in how events are appraised, and this influences the emotional responses (Folkman and Lazarus, 1985; Lazarus, 1991; Lazarus and Lazarus, 1994). The results of this study support this theory in the context of human-technology interaction and emotional user experience and underline the importance of a detailed and organised analysis 
of such a complex phenomenon as emotion in interaction with technology. Although the role of individual differences in the user's emotional experience has been noted before (e.g., Compeau and Higgins, 1995; Shu and Wang, 2011), this notion has not been tested sufficiently 'in action', that is, with real use tasks, while still maintaining experimental control for sufficient observation and manipulation.

Feeling competent during or immediately after an interaction event is the result of being successful in conducting the tasks and, therefore, of viewing one's own skills in a positive light (Saariluoma and Jokinen, 2014). Hence, the effect of the trait of planful problem solving on competence $(\mathrm{H} 2)$ is understandable: being able to cope with task problems with a problem-solving strategy results in experiencing one's own capabilities in a positive light. A user who is inclined to planful problem solving appraises an interaction event with high control potential, which is reflected in feeling more competent. This connection has already been noted in investigations of self-efficacy (Bandura, 1982) and in the context of humantechnology interaction (Compeau and Higgins, 1995; Conati and Maclaren, 2009). However, the connection of being inclined towards planful problem solving and feeling competent during technological tasks has not been previously shown in an experimental setting, within the theoretical framework of the appraisal process of emotion.

Frustration, on the contrary, is the result of encountering obstructions to one's own goals during an interaction (Saariluoma and Jokinen, 2014). Although many sources understandably emphasise the focus on positive experiences (e.g., Desmet, 2012; Hassenzahl, 2008), negative experiences should not be dismissed. Frustration, for example, is a major part of our daily experience with technology (Brinks, 2005; Lazar et al., 2006). Therefore, the support for $\mathrm{H} 3$ that individual differences in frustration tendency have an impact on experiencing frustration is significant. Frustration is indeed a relevant aspect of emotional user experience; however, there are individual differences in how it is experienced. Facing an 
obstacle during the use of technology does not necessarily lead to frustration because, in the face of goal-incongruent events, the user may still cope with the arising emotions.

The competence-frustration model has been developed with experiments and fieldtesting in which people interact with technology (Saariluoma and Jokinen, 2014). It is hence, from its inception, a tool focused on evaluating the emotion process in human-technology interaction. Competence and frustration are closely related to interaction situations in which the user needs to solve problems. Competence is related to successfully completing tasks with ability, and frustration is related to being obstructed from the goals. These circumstances involve primary and secondary appraisal, that is, how the events are related to the goals of the user, and how the user copes with problems using problem-solving or emotion-cantered approach. This implies the usefulness of the competence-frustration model in investigating emotional user experience in demanding human-technology interaction situations. This does not mean that the model covers the totality of what emotional user experience is, but modelling it with psychological theory allows for expanding the model. For example, one important aspect of experience in human-technology interaction, feeling of control (Hassenzahl et al., 2010), can be stated in terms of appraisal theory (Folkman and Lazarus, 1985; Scherer, 2009), which mediates its addition to the model of emotional user experience. $\mathrm{H} 2$ and $\mathrm{H} 3$ are in line with the notion that people generally have two ways to cope during appraisal: problem-solving and emotion-centred approaches (Folkman and Lazarus, 1985; Lazarus, 1991; Lazarus and Lazarus, 1994). As no correlation was observed between the trait factors operationalised from these two ways to cope, it is probable that these traits do not dismiss each other. Therefore, it may be plausible that an individual may have both a high frustration tendency and a high planful problem-solving trait. Questions concerning the connection between the traits, however, would require a larger survey study. The interaction between the two traits was also ignored in the statistical analysis of the study, as the linear 
mixed model for competence did not include frustration tendency as an independent variable, and vice versa. These omissions should be mended in future studies, after a survey revealing the possible combinations of the two traits has been conducted.

The empirical support for $\mathrm{H} 2$ and $\mathrm{H} 3$ already describes how emotional user experience is dependent on the individual differences in coping traits. However, also important is what the user feels right before the use events. The result of the linear mixed model for competence gives support for H4a: self-confidence before the tasks increases competence. The direction of the effect for frustration was as hypothesised (self-confidence decreasing frustration), but the effect was not statistically significant. One possible reason for the larger effect of self-confidence on competence is the similarity between self-confidence and competence scales. Perhaps a scale for measuring states other than self-confidence at the start of the experiment would have correlated with frustration. Although the study reveals a number of relevant individual factors related to emotional experience during humantechnology interaction, future studies should focus on finding more of them.

The partial support for H4 raises an important point. Although mood has been noted as an important antecedent of user experience (Hassenzahl, 2008; Hassenzahl and Tractinsky, 2008), the connection between the user's emotional state before the interaction and emotional user experience responses has not previously been stated as the result of an experimental investigation. The results reported here do not deal with the long-term mood of the participants, but rather their self-confidence immediately before the experimental tasks. However, these results suggest that part of the emotional response to use events is carried from emotional states before the experiment, which suggests a mood effect on emotional user experience. Also of interest is the observed interaction effect between self-confidence and task performance: self-confidence moderates negatively the effect of task performance on competence. If a person is already in a confident state, then the competence resulting from 
being able to conduct tasks is not as visible as it would be for a person who is not as selfconfident but is able to complete the tasks.

These findings open up a large set of future investigations on the effects of the emotional state at the start of the technology use on the emotional states during or immediately after the use. Of course, to measure mood as a time-persistent emotional state, further time points should be used to assess the emotional states of the participants prior to the experiment. The model established herein, therefore, serves as a preliminary demonstration of the effect of mood-congruence. Further, the interaction effect observed between self-confidence and task performance serves as a preliminary result, which should be used to operationalise experiment, which studies this moderation effect, as well as similar possible moderation effects of planful problem solving and frustration tendency, in more detail. As discussed in the introduction, because of appraisal theory, one should expect that the coping traits moderate the effect of task performance on emotion responses, but the investigation of this effect will require further studies.

Emotional user experience is not, of course, only the function of individual differences in coping traits, and in pre-use self-confidence. The influence of task performance on emotional user experience (H1) was observed to be large. This finding provides construct validity to the competence-frustration model of emotional user experience, and suggests effect sizes for further studies. The standardised coefficients of task performance in the two models (.63 for competence and -.59 for frustration) can be contrasted with a meta-analysis, in which correlations between objective task-performance measures and subjective measures of satisfaction were found to be relatively small, from .16 to .25 (Hornbæk and Law, 2007). It is possible that the role of task performance was emphasised, because the participants were restricted to conduct the tasks in a limited timeframe. However, it is also possible that because the studies reviewed by Hornbæk and Law (2007) did not consider the complete 
framework of emotional user experience presented herein, the effects of coping traits and self-confidence - not measured in the reviewed studies - were confounding the results, which resulted in small effect sizes of objective performance on subjective experience. This supports the use of a competence-frustration model, augmented with the notions of coping and self-confidence antecedents, for investigating the emotion process in human-technology interaction.

The context of the study, ordinary desktop applications, was chosen because the discussion and experimentation on the effects of coping traits on emotional user experience is easier in very familiar settings. It should be noted, however, that the results do not necessarily generalise to, for example, leisure context, such as games, or more complex interaction scenarios. With computer games, for example, a certain amount of frustration may be necessary for good experience (Baker et al., 2010), a notion that is not considered in the hypotheses of this study. However, it is still maintained that the overall model of how coping affects the user's emotional experience is also valid in a leisure context. In a computer game, challenge is expected, but, to enjoy the challenges, the player needs to be able to solve the challenges and cope with the frustrations. Therefore, while the competence-frustration model has not been tested with computer games or in other leisure contexts, it a plausible hypothesis for future studies that the mechanism of feeling competent or feeling frustrated in a leisure context is similar to that in work contexts. The relative strengths of the associations explored herein, of course, can vary notably in different contexts, so that, for example, frustration tendency may play a larger role in computer games than it does in a work environment. Moreover, the competence-frustration model has been tested with complex interaction (Saariluoma and Jokinen, 2014), and it should therefore be possible to translate the results of this study to complex environments. 
Further, it should be noted that performance is certainly not the only goal of the user in human-technology interaction. Rather, people use technology for a variety of personal goals, and, thus, good task performance is goal-congruent only in the sense that the completed tasks support the psychological needs of the user, such as the need to feel safe or competent (Hassenzahl et al., 2010). However, while the connection between the artificial tasks and the needs of the user is not the same as it would be in a natural setting, it is probable that the participants wanted to perform well and wanted to feel competent during the experiment. In this case, it was also helpful that the tasks were derived from ordinary office work, because in all likelihood, the participants felt that being able to perform well in them is relevant for their current life goals, such as being able to use information technology in daily student work.

\section{Methodological considerations}

Although the main result of the study is the support for the proposed model of individual differences in the competence-frustration model of emotional user experience, the results also serve to support the methodological position of user experience as mental contents (Saariluoma and Jokinen, 2014). As discussed in the introduction, emotional user experience occurs in the process of appraisal, in which the personal significance of an event and the coping potential of the user are appraised. While the appraisal process is not completely conscious, it does have a conscious aspect, represented as feelings (Scherer, 2009). The study of these feelings, for example, in such concepts as techno-competence or techno-frustration, is possible via conceptualising emotional user experience as the emotional contents of the user's mental representations concerning the interaction. This methodological position, however, still requires further defence.

The use of questionnaires to elicit data on emotional experience has been criticised from various perspectives (Schorr, 2001). It is possible, for example, that participants are reporting their general knowledge concerning emotions, not their emotional states. If this was 
the case in the study, then the observed emotional responses would not reflect the participants' actual emotional responses, but rather, for example, how the participants expect that they should respond. While this is of course possible, the statistical model from the experiment provides validity for the competence-frustration model. Task performance is shown to have a strong correlation with emotional user experience (H1). This of course could reflect at least partially the fact that the participants think, in general, that if they are not successful in their tasks, they should report low competence and high frustration. In this case, the variances of competence and frustration at least partially would be accounted by the participant's general knowledge about what is expected of them. However, it is less feasible to claim that the participants could reflect on the constructs about their coping tendencies and use this information to respond to the questionnaires, inferring, for example, that having reported a high frustration tendency, that a high frustration response would be expected of them. Correlations between individual coping traits and in the models for competence and frustration are more complex than what can be accounted for by the participants utilising their general information to reflect on what they believe is assumed of them.

Although observing the expected correlations between the pre- and post-test questionnaire responses and task events provides validity for the utilised methodology, it is true that the two trait factors of the study are not the same as actual coping during the tasks. The results therefore suggest that individual differences in coping are relevant in emotion research in human-technology interaction; however, the mechanisms of coping during different tasks, different goals, and different means of problem solving still need to be examined in greater detail. Conducting an experiment utilising protocol analysis with a focus on problem solving and emotional experience during interaction tasks and connecting the findings to the coping traits of the participants would be one interesting option in connecting the mechanisms of coping with coping traits. 
Another criticism of the study's methodology is the argument that emotion should not be measured nor theorised within the information-processing model of human activity (Boehner et al., 2007). This line of thought follows the cultural or constructivist perspective of human activity (Law et al., 2014): conscious emotional experience is conceptualised using cultural categories, and, hence, its measurement and reduction back to cognitive processes is not possible (Barrett, 2006; Boehner et al., 2007). It is possible, however, to accept that experience and communication of emotion rely on cultural constructs and still accept that there are cognitive, non-conscious processes that underlie our emotional states (Scherer, 2009). For example, to understand why a user is frustrated, it is necessary to understand how the experience of frustration occurs during an appraisal process. However, in the end, what is relevant is the explanation of the experience from all relevant perspectives. The appraisal process can explicate the mechanism from an interaction event to emotional user experience, but the explanation of techno-frustration requires facts about the circumstances of the use, as well as the beliefs and desires of the user. Only after these facts are understood does the explanation of frustration via the process of appraisal become meaningful.

Understanding emotion in terms of the appraisal process establishes an important connection between emotion and cognition. This connection has been demonstrated theoretically and empirically, in terms of how emotion influences cognitive processes (Bower, 1981) and how cognitive factors determine emotional states (Schachter and Singer, 1962). Hence, the discussion on whether to focus on cognition or emotion in humantechnology interaction research is not relevant (Bødker, 2006): research on either assumes the other. As the model of emotional user experience explored herein states, it is as important to consider the performance of the use, as it is to consider the individual differences coping with problems during the interaction. These are all related to the mental processes of the user, and to the experience that the user has about the technology. 


\section{Emotional user experience and design}

The notion of designing for experiences or facilitating certain experiences with design solutions has been adapted in a variety of applications, from consumer-oriented e-commerce (Nielsen et al., 2000) and drinking glasses (Saariluoma et al., 2013) to business-oriented elevators (Rousi, 2013) and port cranes (Koskinen et al., 2013). To make the most of userexperience design, it is important to be able to understand scientifically what user experience is. This entails analysis, operationalisation, and study of the dimensions of user experience. One of the main dimensions of user experience, emotion, has been investigated in this article, with modern psychological theorising and methodology, namely, with a cognitive theory of emotion. The results indicate that individual coping traits have a significant role in the appraisal of everyday technological interactions and subsequent conscious emotional representations. The results can be utilised to make evaluations of emotional user experience of different products more valid, because theorising a measurement instrument for user experience with a cognitive theory of emotion gives credibility to evaluations using that instrument. Further, the insight offered by the extensive theoretical and empirical psychological work on this topic can be used to make sense of the results from those instruments. In the experiments reported here, for example, some amount of the emotional responses was explained by individual differences in factors, which did not relate to the used technologies. This makes the results, which are directly related to the technology, less confounded.

The results remind that individual differences should be considered in technology design, and not only in basic research on user experience. For example, whereas some people may prefer to have helpful information available only on demand, others may require active support in problem solving. This notion is well discussed in research on user modelling. In addition, modelling user's emotional states for developing adaptive interfaces has also been 
studied (Picard et al., 2001). User traits have, for example, been linked to emotional states in modelling user affect (Conati and Maclaren, 2009), but, although the existence of traits as emotional antecedents has been acknowledged, detailed discussion on what these traits are and what the mechanisms from traits to emotional states are is necessary, and the present study provides outlines for it. Understanding the relevant individuating factors in emotional user experience is an important aspect in explaining emotional experience in humantechnology interaction, and it is advantageous, for example, in designing efficient user modelling and adaptive, personified interfaces.

The competence-frustration model of emotional user experience explored still needs further research to simplify its use in technology design. Laboratory experimentation is, up to a point, suitable for model building, but the real user experience occurs, of course, in naturalistic settings, with users who have actual goals, both work-related and life-related, and with actual work tasks. Therefore, one crucial step in constructing the competence-frustration model of emotional user experience as the function of individual differences and events during the use should hence be to investigate the working of the model in field settings. The competence-frustration model of emotional user experience has been validated in naturalistic settings (Saariluoma and Jokinen, 2014), and the process should be taken as a model for further studies of ecological validity.

\section{References}

Allen, B., 2000. Individual differences and the conundrums of user-centered design: Two experiments. Journal of the American Society for Information Science, 51(6), 508-520.

Baddeley, A., 2007. Working memory, thought, and action. Oxford University Press, Oxford. Baker, R. S .J. d., D’Mello, S. K., Rodrigo, M. M. T., Graesser, A. C., 2010. Better to be frustrated than bored: The incidence, persistence, and impact of learners' cognitive- 
affective states during interactions with three different computer-based learning environments. International Journal of Human-Computer Studies, 68(4), 223-241.

Bandura, A., 1977. Self-efficacy: Toward a unifying theory of behavioral change. Psychological Review, 84(2), 191-215.

Bandura, A., 1982. Self-efficacy mechanism in human agency. American Psychologist, 37(2), 122-147.

Barrett, L. F., 2006. Solving the emotion paradox: Categorization and the experience of emotion. Personality and Social Psychology Review, 10(1), 20-46.

Beaudry, A., Pinsonneault, A., 2005. Understanding user responses to information technology: A coping model of user adaptation. MIS Quarterly 29(3), 493-524.

Berkowitz, L., 1989. Frustration-aggression hypothesis: Examination and reformulation. Psychological Bulletin, 106(1), 59-73.

Boehner, K., DePaula, R., Dourish, P., Sengers, P., 2007. How emotion is made and measured. International Journal of Human-Computer Studies, 65(4), 275-291.

Bower, G. H., 1981. Mood and memory. American Psychologist, 36(2), 129-148.

Brave, S., Nass, C., 2003. Emotion in human-computer interaction. In: Sears, Jacko (Eds.), The human-computer interaction handbook: Fundamentals, evolving technologies and emerging applications, Lawrence Erblaum Associates, Mahwah, NJ, pp. 53-68.

Brinks, M., 2005. Aggression gegen Computer: eine wissenschaftliche Untersuchung eines alltäglichen Phänomens. Ibidem-Verlag, Stuttgart.

Bødker, S., 2006. When second wave HCI meets third wave challenges. In: Proceedings of the 4th Nordic Conference on Human-Computer Interaction, ACM, pp. 1-8.

Compeau, D. R., Higgins, C. A., 1995. Computer self-efficacy: Development of a measure and initial test. MIS Quarterly, 19(2), 189-212. 
Conati, C., Maclaren, H., 2009. Empirically building and evaluating a probabilistic model of user affect. User Modeling and User-Adapted Interaction, 19(3), 267-303.

DiStefano, C., Zhu, M., Mindrila, D., 2009. Understanding and using factor scores:

Considerations for the applied researcher. Practical Assessment, Research \& Evaluation 14(20), 1-11.

Dennett, D. C., 1988. Quining qualia. In: Marcel, Bisiach (Eds.), Consciousness in contemporary science, Oxford University Press, New York, pp. 381-414.

Desmet, P. M., 2012. Faces of product pleasure: 25 positive emotions in human-product interactions. International Journal of Design, 6(2), 1-29.

Desmet, P. M., Hekkert, P, 2007. Framework of product experience. International Journal of Design, 1(1), 57-66.

Ericsson, K. A., Simon, H. A., 1984. Protocol analysis: Verbal reports as data. MIT Press, Cambridge, MA.

Fodor, J. A., 1985. Fodor's guide to mental representation: The intelligent auntie's vademecum. Mind, 94(373), pp. 76-100.

Folkman, S., Lazarus, R. S., 1985. If it changes, it must be a process: Study of emotion and coping during three stages of a college examination. Journal of Personality and Social Psychology, 48, 150-170.

Folkman, S., Lazarus, R. S., 1988. Manual for the ways of coping questionnaire. Mind Garden, Palo Alto, CA.

Forgas, J. P., Bower, G. H., 1987. Mood effects on person-perception judgments. Journal of Personality and Social Psychology, 53(1), 53-60.

Frijda, N. H., 1988. The laws of emotion. American Psychologist, 43(5), 349-358. 
Hassenzahl, M., 2008. User experience (UX): towards an experiential perspective on product quality. In: Proceedings of the 20th International Conference of the Association Francophone d'Interaction Homme-Machine, ACM, pp. 11-15.

Hassenzahl, M., 2010. Experience design - Technology for all the right reasons. Morgan \& Claypool, San Francisco.

Hassenzahl, M., Diefenbach, S., Göritz, A., 2010. Needs, affect, and interactive products Facets of user experience. Interacting with Computers, 22(5), 353-362.

Hekkert, P., Mostert, M., Stompff. G., 2003. Dancing with a machine: A case of experiencedriven design. In: Proceedings of the 2003 International Conference on Designing Pleasurable Products and Interfaces, ACM, pp. 114-119.

Hornbæk, K., 2006. Current practice in measuring usability: Challenges to usability studies and research. International Journal of Human-Computer Studies, 64(2), 79-102.

Hornbæk, K., Law, E., 2007. Meta-analysis of correlations among usability measures. In: Proceedings of the SIGCHI Conference on Human Factors in Computing Systems, ACM, pp. 617-626.

Hox, J. J., 2010. Multilevel analysis ( $2^{\text {nd }}$ ed). Routledge, Hove.

Izard, C. E., 2007. Basic emotions, natural kinds, emotion schemas, and a new paradigm. Perspectives on Psychological Science, 2(3), 260-280.

Kavanagh, D. J., Bower, G. H., 1985. Mood and self-efficacy: Impact of joy and sadness on perceived capabilities. Cognitive Therapy and Research, 9(5), 507-525.

Koskinen, H., Karvonen, H., Tokkonen, H., 2013, User experience targets as design drivers: A case study on the development of a remote crane operation station, Proceedings of the 31st European Conference on Cognitive Ergonomics, Article No. 25. 
Law, E., Roto, V., Hassenzahl, M., Vermeeren, A., Kort, J., 2009. Understanding, scoping and defining user experience: a survey approach. In: Proceedings of the CHI 2009 Conference on Human Factors in Computing Systems, ACM, pp. 719-728.

Law, E., van Schaik, P., Roto, V., 2014. Attitudes towards user experience (UX) measurement. International Journal of Human-Computer Studies, 72(6), 526-541.

Lazar, J., Jones, A., Shneiderman, B., 2006. Workplace user frustration with computers: An exploratory investigation of the causes and severity. Behaviour \& Information Technology, 25(03), 239-251.

Lazarus, R. S., 1991. Emotion and adaptation. Oxford University Press, New York. Lazarus, R. S., 2001. Relational meaning and discrete emotions. In: Scherer, Schorr, Johsntone (Eds.), Appraisal processes in emotion, Oxford University Press, New York, pp. 37-67.

Lazarus, R. S., Lazarus, B. N., 1994. Passion and reason. Oxford University Press, New York.

Lazarus, R. S., Averill, J. R., Opton, E. M., 1970. Towards a cognitive theory of emotion. In: Arnold (Ed.), Feelings and emotions, Academic Press, New York, pp. 207-232).

Lichtenstein, A., Oehme, A., Kupschick, S., Jürgensohn, T., 2008. Comparing two emotion models for deriving affective states from physiological data. In: Peter, Beale, (Eds.), Affect and emotion in human-computer interaction, Springer, Berlin, pp. 35-50.

Mahlke, S., Minge, M., 2008. Consideration of multiple components of emotions in humantechnology interaction. In: Peter, Beale (Eds.), Affect and emotion in human-computer interaction, Springer, Berlin, pp. 51-62.

Mahlke, S., Thüring, M., 2007. Studying antecedents of emotional experiences in interactive contexts. In: Proceedings of the SIGCHI Conference on Human Factors in Computing Systems, ACM, pp. 915-918. 
Nielsen, J., Molich, R., Snyder, C., Farrell, S., 2000. E-commerce user experience. Nielsen Norman Group, Fremont, CA.

Norman, D. A., 2004. Emotional design. Basic Books, New York. Picard, R. W., Vyzas, E., Healey, J., 2001. Toward machine emotional intelligence: Analysis of affective physiological state. IEEE Transactions on Pattern Analysis and Machine Intelligence, 23(10), 1175-1191.

Power, M. J. Dalgleish, T., 1997. Cognition and emotion: From order to disorder. Psychology Press, Hove.

Roto, V., Law, E., Vermeeren, A., Hoonhout, J., 2011. User experience white paper. Retrieved on January, 2014, from http://www.allaboutux.org/files/UX-WhitePaper.pdf

Rousi, R., 2013. The experience of no experience: Elevator UX and the role of unconscious experience. In: Proceedings of International Conference on Making Sense of Converging Media, ACM, pp. 289-292.

Russell, J. A., 1980. A circumplex model of affect. Journal of Personality and Social Psychology, 39(6), 1161-1178.

Saariluoma, P., 2004. Explanatory frameworks in interaction design. In: Pirhonen, Isomäki, Roast, Saariluoma (Eds.), Future interaction design, Springer, London, pp. 67-83.

Saariluoma, P., Jokinen, J. P. P., 2014. Emotional dimensions of user experience: A user psychological analysis. International Journal of Human-Computer Interaction, 30(4), 303320.

Saariluoma, P., Jokinen, J. P. P., Kuuva, S., Leikas, J., 2013. User experience as mental contents. In: Proceedings of the 10th European Academy of Design Conference, Chalmers University of Technology, Gothenburg.

Saariluoma, P., Oulasvirta, A., 2010. User psychology: Re-assessing the boundaries of a discipline. Psychology, 1(5), 317-328. 
Saracevic, T., 1991. Individual differences in organizing, searching and retrieving Information. In: Proceedings of the ASIS Annual Meeting, Vol. 28, pp. 82-86.

Satterthwaite, F. E., 1941. Synthesis of variance. Pyschometrika, 6, 309-316. Schachter, S, Singer, J. E., 1962. Cognitive, social and psychological determinants of emotional state. Psychological Review, 69, 379-399.

Scherer, K. R., 1994. Toward a Concept of 'Modal Emotions'. In: Ekman, Davidson (Eds.), The Nature of Emotion: Fundamental Questions, Oxford University Press, New York, pp. 25-31.

Scherer, K. R., 2001. Appraisals considered as a process of multilevel sequential checking. In: Scherer, Schorr, Johnstone (Eds.), Appraisal processes in emotion: Theory, methods, research, Oxford University Press, New York, pp. 92-120.

Scherer, K. R., 2005. What are emotions? And how can they be measured? Social Science Information, 44(4), 695-729.

Scherer, K. R., 2009. The dynamic architecture of emotion: Evidence for the component process model. Cognition and Emotion, 23(7), 1307-1351.

Schunk, D. H., 1983. Ability versus effort attributional feedback: Differential effects on selfefficacy and achievement. Journal of Educational Psychology, 75, 848-856.

Sedikides, C., 1995. Central and peripheral self-conceptions are differentially influenced by mood: Tests of the differential sensitivity hypothesis. Journal of Personality and Social Psychology, 69(4), 759-77.

Shieh, Y. Y., Fouladi, R. T., 2003. The effect of multicollinearity on multilevel modeling parameter estimates and standard errors. Educational and Psychological Measurement, 63(6), 951-985. 
Shu, Q., Tu, Q., Wang, K., 2011. The impact of computer self-efficacy and technology dependence on computer-related technostress: A social cognitive theory perspective. International Journal of Human-Computer Interaction, 27(10), 923-939.

Thüring, M., Mahlke, S., 2007. Usability, aesthetics and emotions in human-technology interaction. International Journal of Psychology, 42(4), 253-264.

Venkatesh, V., 2000. Determinants of perceived ease of use: Integrating control, intrinsic motivation, and emotion into the technology acceptance model. Information Systems Research, 11(4), 342-365.

Watson, D., Clark, L. A., 1997. Measurement and mismeasurement of mood: Recurrent and emergent issues. Journal of Personality Assessment, 68(2), 267-296.

Watson, D., Clark, L. A., Tellegen, A. 1988. Development and validation of brief measures of positive and negative affect: the PANAS scales. Journal of Personality and Social Psychology, 54(6), 1063-1070.

Wright, P., Wallace, J., McCarthy, J., 2008. Aesthetics and experience-centered design. ACM Transactions on Computer-Human Interaction (TOCHI), 15(4), 18-1-18-21 


\section{Acknowledgments}

This research is supported by the Finnish Funding Agency for Technology and Innovation (TEKES) and the Finnish Metals and Engineering Competence Cluster (FIMECC)

programme UXUS (User experience and usability in complex systems).

The author thanks Piia Perälä (University of Jyväskylä), who helped in conducting the experiment reported herein, and prof. Pertti Saariluoma and dr. Tuomo Kujala (University of Jyväskylä), for helpful comments about the manuscript.

Table 1.

Questionnaire items of the factors used in the experiment and reliabilities, presented as both factor score covariance coefficients and Cronbach's alpha. Scores for competence and frustration are calculated for the pooled data.

\begin{tabular}{lc}
\hline Factors and items & $\begin{array}{c}\text { Facto } \\
\text { loadin }\end{array}$ \\
\hline Planful problem solving & \\
When I encounter a technological problem ... & .46 \\
I am capable of searching the internet or the manual for solutions. & .79 \\
I won't give up before solving it. & .81 \\
I try to solve it independently. & .68 \\
I utilise my prior knowledge and experience in solving it. &
\end{tabular}

Frustration tendency

When a technological equipment, application, or service does not work as expected or otherwise works exceedingly badly and is frustrating ...

I vent my frustration physically.

I blame the equipment, application, or service. $\quad .59$

I'm not able to cope calmly with the problem.

it takes a long time for me to recover from my frustration.

$\begin{array}{lll}\text { Self-confidence before the test } & .85 & .68\end{array}$

Currently, Ifeel ...

certain.

determined. $\quad .91$

$\begin{array}{ll}\text { ready. } & .91\end{array}$

\section{Competence}

During the tasks I felt ...

successful.

determined.

efficacious.

vigilant. 
During the tasks I felt ...

frustration. $\quad .79$

anxiety. $\quad .70$

confusion. $\quad .69$

annoyance. $\quad .80$

Note. $N=50$.

Table 2.

The linear mixed model for competence displaying the fixed coefficients with standard errors and standardised coefficients. The repeated measures are given as the random part of the model.

\begin{tabular}{|c|c|c|c|c|}
\hline \multirow[b]{3}{*}{ Intercept } & \multicolumn{4}{|c|}{ Fixed part } \\
\hline & $\mathrm{F}$ & $\mathrm{df} 1, \mathrm{df} 2$ & Coefficient (s.e.) & Std. coef. \\
\hline & $41.7 * *$ & 5,174 & $-0.87 * *(0.08)$ & \\
\hline Task performance & $162.8 * *$ & 1,183 & $0.19 * *(0.02)$ & .63 \\
\hline Planful problem solving & $5.6^{*}$ & 1,178 & $0.22 *(0.09)$ & .19 \\
\hline Self-confidence & $13.8^{* *}$ & 1,160 & $0.34 * *(0.09)$ & .33 \\
\hline $\begin{array}{l}\text { Planful problem solving } \times \text { task } \\
\text { performance }\end{array}$ & 0.2 & 1,166 & $-0.01(0.02)$ & \\
\hline $\begin{array}{l}\text { Self-confidence } \times \text { task } \\
\text { performance }\end{array}$ & $8.0^{* *}$ & 1,184 & $-0.05 * *(0.02)$ & \\
\hline & \multicolumn{4}{|c|}{ Random part } \\
\hline$\sigma_{1}$ & & & $2(0.11)$ & \\
\hline$\sigma_{2}$ & & & $5(0.08)$ & \\
\hline$\sigma_{3}$ & & & $3(0.11)$ & \\
\hline$\sigma_{4}$ & & & $5(0.09)$ & \\
\hline
\end{tabular}

Note. $N=50$, cases included $=198$. s.e. $=$ standard error. Std. coef. $=$ standardised coefficient. $\sigma=$ standard deviation of the random parameter; $1=$ text processor; $2=$ image editor; $3=$ web browser; and $4=$ presentation editor. Because of the Satterthwaite's approximation, the degrees of freedom (df2) vary between the independent variables. $* \mathrm{p}<.05, * * \mathrm{p}<.01$. 
Table 3.

The linear mixed model for frustration displaying the fixed coefficients with standard errors and standardised coefficients. The repeated measures are given as the random part of the model.

\begin{tabular}{|c|c|c|c|c|}
\hline \multirow[b]{3}{*}{ Intercept } & \multicolumn{4}{|c|}{ Fixed part } \\
\hline & $\mathrm{F}$ & df1, df2 & Coefficient (s.e.) & Std. coef. \\
\hline & $23.6^{* *}$ & 5,184 & $0.76 * *(0.09)$ & \\
\hline Task performance & $98.8^{* *}$ & 1,193 & $-0.17 * *(0.02)$ & -.59 \\
\hline Frustration tendency & $9.7 * *$ & 1,181 & $0.35 * *(0.11)$ & .35 \\
\hline Self-confidence & 3.4 & 1,186 & $-0.18(0.10)$ & \\
\hline $\begin{array}{l}\text { Frustration tendency } \times \text { task } \\
\text { performance }\end{array}$ & 2.1 & 1,193 & $-0.03(0.02)$ & \\
\hline $\begin{array}{l}\text { Self-confidence } \times \text { task } \\
\text { performance }\end{array}$ & 0.6 & 1,190 & $0.01(0.02)$ & \\
\hline $\begin{array}{l}\sigma_{1} \\
\sigma_{2} \\
\sigma_{3} \\
\sigma_{4}\end{array}$ & & & $\begin{array}{l}\text { Idom part } \\
70(0.15) \\
47(0.10) \\
47(0.10) \\
55(0.11)\end{array}$ & \\
\hline
\end{tabular}

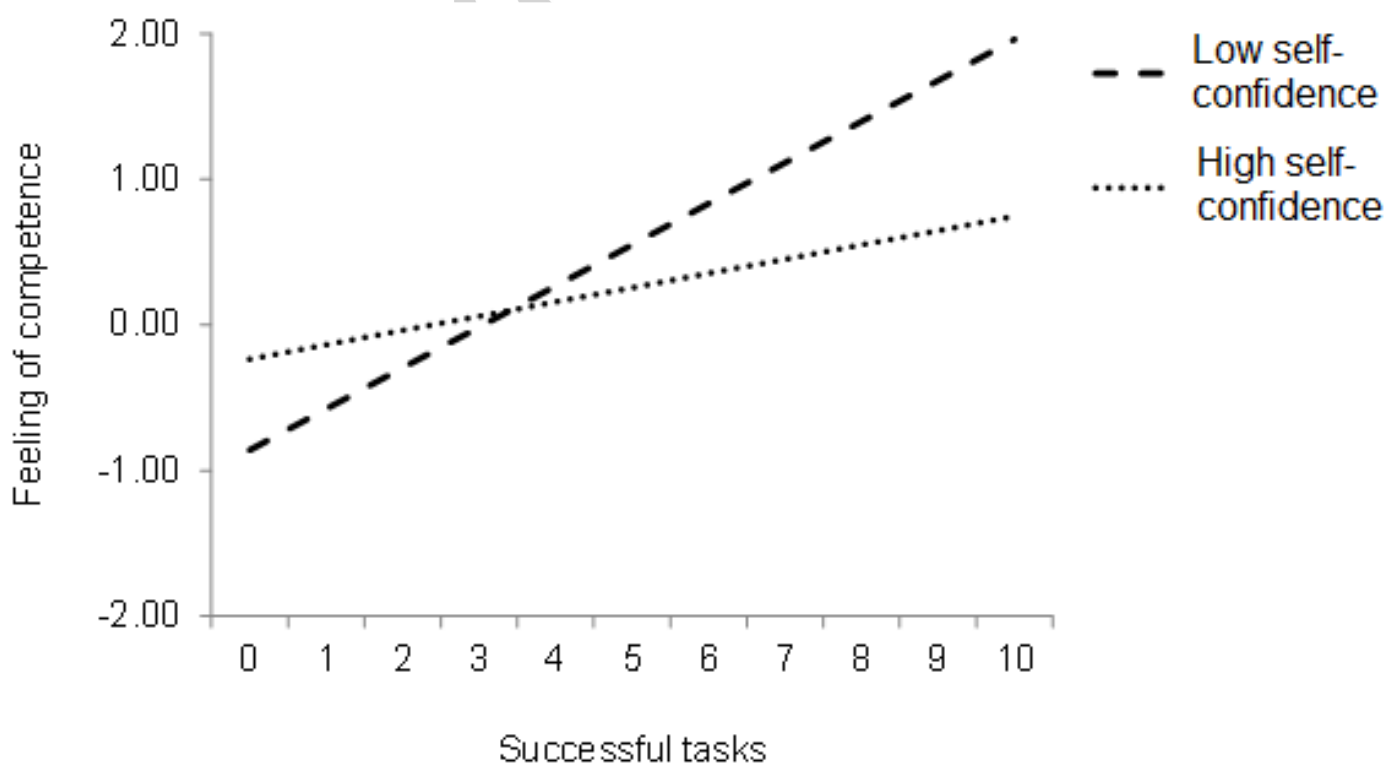

Figure 1. Regression lines for competence by tasks completed and by self-confidence. Low and high self-confidence are calculated as two standard deviations from the mean. 


\section{Author Vitae}

Jussi P. P. Jokinen is a doctoral student of cognitive science in University of Jyväskylä,

Finland. His Research interest is in human-technology interaction with a focus on emotional user experience. Other interests include cognitive studies of design thinking and innovations.

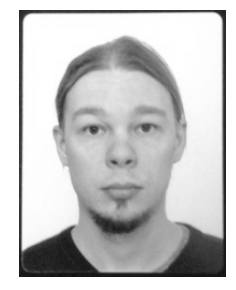

- Individual differences in emotional responses in human-technology interaction were investigated.

- Competence is affected by individual differences in planful problem solving trait.

- Frustration is affected by individual differences in frustration tendency trait.

- Self-confidence of the user affects emotional user experience. 